\title{
SEM and XEDS Analysis of Paint Layers on a 1907 Model G White Steam Touring Car from The Henry Ford Museum Collection
}

\author{
Steven King, ${ }^{*}$ Clara Deck,, ${ }^{* *}$ Cathy Selvius DeRoo, ${ }^{* * *}$ and John Mansfield* \\ * North Campus Electron Microbeam Analysis Laboratory, 417 SRB, University of Michigan, 2455 \\ Hayward, Ann Arbor MI 48109-2143** The Henry Ford Museum, 20900 Oakwood Boulevard \\ Dearborn, MI 48124-4088, *** Detroit Institute of Arts, 5200 Woodward Avenue, Detroit, Michigan \\ 48202
}

\begin{abstract}
A 1907 Model G White Steam Touring car (Figure 1(a)) in the collection of the Henry Ford Museum was of particular interest to the museum's conservators since it was believed that, unlike most of the automobiles in the collection from this era, the painted surface on this touring car is original. The museum's founder, Henry Ford, did not hesitate to restore damaged components and had every resource at his disposal to repaint and re-make parts. Many cars were also restored before coming to the museum. The fact that this specimen was not heavily restored is important, since the car is from an era where the early automobile paint processes were being derived from the coach builders' craft. The early painting methods applied to automobile bodywork were rarely documented, and transmission of the techniques was typically from an experienced master of the trade to apprentices. The sequence of primers, undercoats and finish coats is of interest in the attempts to conserve the car and its appearance without seriously changing the original materials. The body of this car is, unusually for the period, an aluminum alloy (with a wooden frame structure).
\end{abstract}

The analysis of the paint from this car has been carried out by collaborators from The Henry Ford, The Detroit Institute of Arts and the University of Michigan Electron Microbeam Analysis Laboratory, where the examination is an Undergraduate Research Opportunities Program (UROP) project. Samples for analysis were extracted in the form of small flakes from a number of locations on the body of the car (Figure 1(b) and (c)). The flakes were embedded in epoxy resin and microtomed to reveal the cross sectional structure of the layers of paint. Examination in polarized light (Figure 2(a)) revealed the presence of at least six distinct layers, all but one of which (layer 5) were seen to be comprised of fine grain particles. Environmental scanning electron microscopy (ESEM) of the layers (Figure 1(b)) also revealed minimal structure in layer 5. X-ray energy dispersive spectrometry (XEDS) analysis of the layers (Figure 3) revealed that layer 1, that closest to the metal of the body, was rich in lead, suggesting a lead white primer coat. The second layer comprise of a complex mixture of $\mathrm{Fe}, \mathrm{O}, \mathrm{Ti}, \mathrm{K}, \mathrm{Si}, \mathrm{Pb}, \mathrm{Ca}, \mathrm{Al}$ and Ti. The third layer actually seems to be two or even three layers, comprising of $\mathrm{Pb}$, Ti and $\mathrm{Si}$. The featureless 5th layer is principally carbon and an FTIR analysis of small samples extracted from this layer indicate that it could comprise of a drying oil or varnish, probably tung oil or dammar varnish. The final top layer of the paint structure, which is about $8 \mu \mathrm{m}$ thick, is rich in $\mathrm{Cr}, \mathrm{Fe}$, Ti and $\mathrm{Pb}$, re-raising the question of whether this is a "touch-up" overcoat added at a later date. A more protracted analysis of the spectrum maps with the aid of the AXSIA ${ }^{2}$ software package from Sandia National Labs, is now being undertaken, to identify the phases in the layers. FIB sectioning is planned to allow cross-sectional TEM analysis of the finer grained material.

\section{References}

1. http://www.ohiohistorycentral.org/entry.php?rec=1006

2. Automated eXpert Spectral Image Analysis, Sandia National Laboratories. 


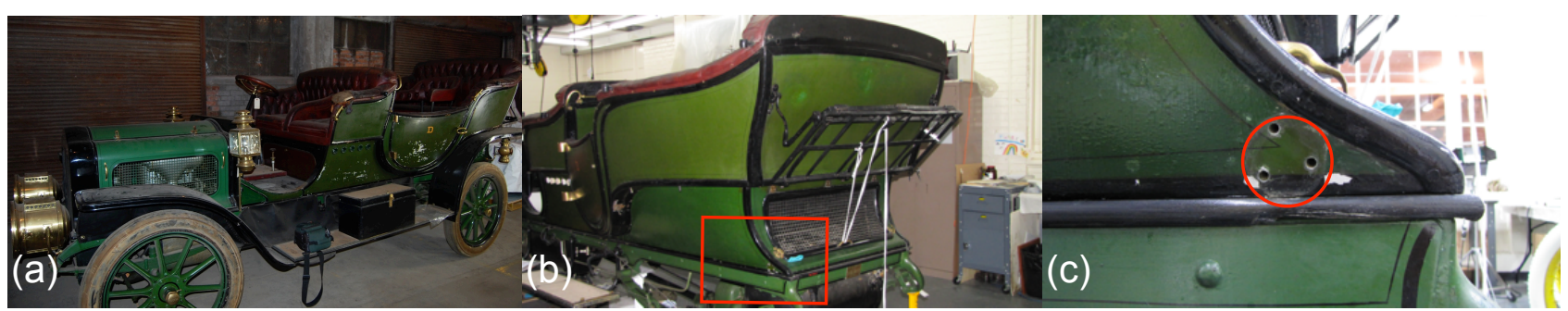

Figure 1. (a) White car prior to current conservation workshop at The Henry Ford Museum. (b) Rear view of vehicle with one area from which paint was sampled outlined in red. (c) Paint sample for microanalysis removed from region outlined by red circle.

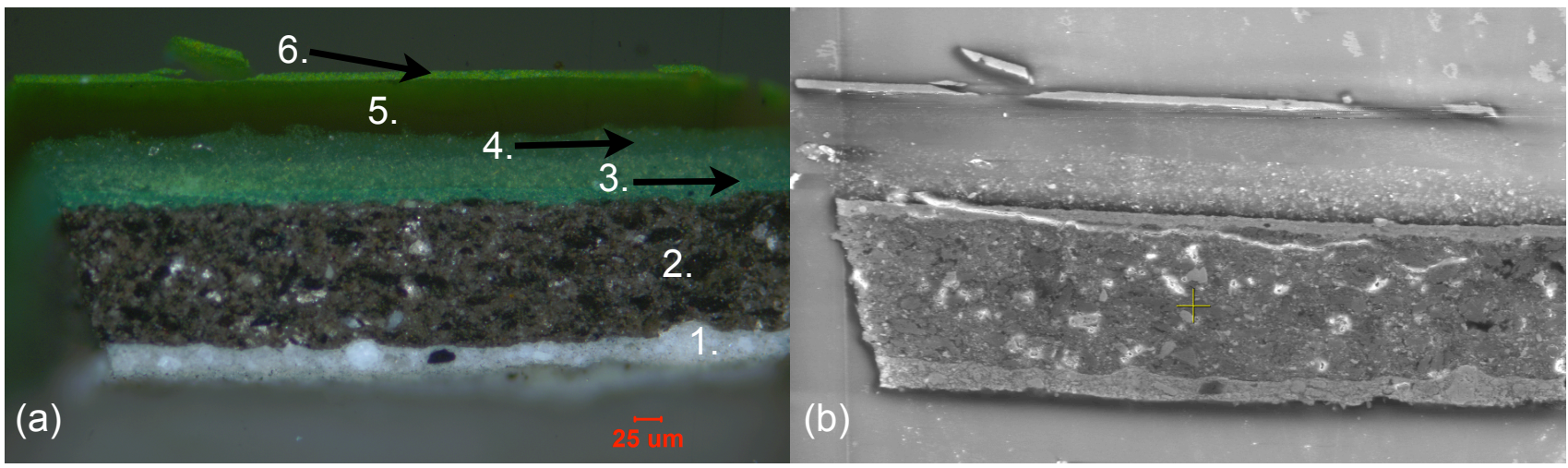

Figure 2. Cross section of paint flake imaged (a) under cross polarizers and (b) in the ESEM.

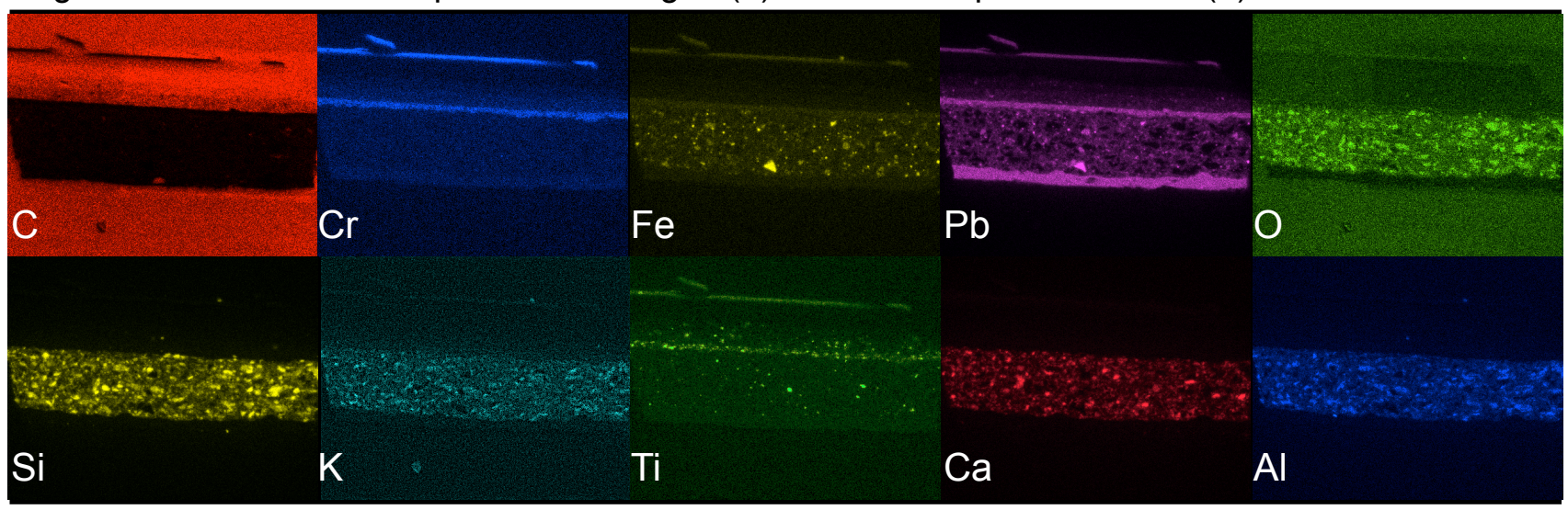

Figure 3. X-ray maps of the paint cross section illustrating the markedly different chemistries of each layer.

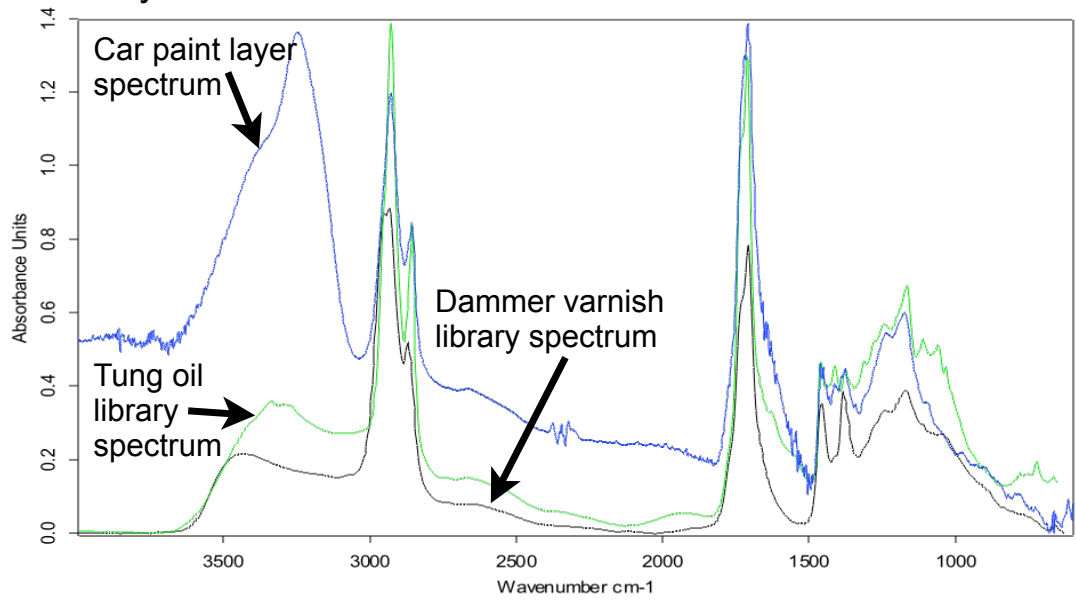

Figure 4. Figure 4. Micro-FTIR spectrum from Bruker Hyperion 2000/Tensor 27 spectrometer, transmission mode, $15 x$ objective, sample mounted in a diamond cell, a 256 scan acquisition. Spectrum was compared to the Infrared and Raman Users Group (IRUG) Library of artists' materials, with aged tung oil and aged dammar varnish providing the best matches to layer 5 material. 